\title{
Düzenleyici Ekosistem Hizmetlerinde Toprak Erozyonunun Haritalanması: Göksu Havzası Örneği
}

\author{
Ahmet ÇiLEK ${ }^{* 1}$ \\ ${ }^{1}$ Çukurova Üniversitesi, Mimarlık Fakültesi, Peyzaj Mimarlı̆̆ı Bölümü, Adana
}

Geliş tarihi: 30.04 .2021

Kabul tarihi: 30.06 .2021

$\ddot{\mathbf{O} z}$

Toprak erozyonu karasal ekosistemlerde önemli bir küresel çevre sorunu olarak, çevresel kaliteyi ve sosyal ekonomiyi önemli ölçüde etkiler. Karasal ekosistemler, toprağı rüzgar ve su erozyonundan koruyarak insanlara insan refahını sağlayan temel ekosistem hizmetlerinden biri olan toprak erozyon kontrol hizmeti sağlamaktadır. Genellikle yanlış arazi kullanımı ve antropojenik etkilerden dolayı özellikle eğimli arazilerde toprağın tutucu bitki örtüsü azalması ya da yok olması sonucunda topraklar aşınmakta ve taşınmaktadır. Göksu havzası, ülkemizde önemli şiddetli toprak erozyonuna maruz kalan bölgelerinden birisidir. Bu çalı̧̧mada bir ekosistem hizmeti olarak erozyon düzenlemesini haritalamak için RUSLE erozyon modelleme yöntemini kullanarak Göksu Havzası için yıllık toprak kaybının belirlemesi ve sürdürülebilir yönetim/planlama çalışmalarına entegrasyonu amaçlanmıştır. RUSLE yönteminde Yağış faktörü $(R)$, toprak erozyon duyarlılığı faktörü (K), Eğim uzunluğu faktörü (L), eğim dikliği faktörü (S), Arazi Örtüsü ve Alan Kullanım Faktörleri (C) ve erozyon kontrol faktörü (P) kullanılarak bir hesaplama yapılmaktadır. Elde edilen sonuçlar, ekosistem hizmetlerini sağlamak için faktörlerin potansiyelini ortaya koymakta ve peyzaj yönetimi için önemli bilgiler sağlamaktadır.

Anahtar Kelimeler: Düzenleyici ekosistem hizmetleri, Toprak erozyonu, Doğu Akdeniz havzası, RUSLE

\section{Mapping Soil Erosion in Regulating Ecosystem Services: The Case of Göksu Basin}

\begin{abstract}
Soil erosion is a major global environmental problem in terrestrial ecosystems, significantly affecting environmental quality and social economy. Terrestrial ecosystems provide soil erosion control service, one of the basic ecosystem services that provide human well-being to people by protecting the soil from wind and water erosion. Soils are eroded and transported due to the decrease or disappearance of the soil conservative vegetation, especially in sloping lands, due to generally inappropriate land use and anthropogenic effects. Göksu basin is one of the regions in our country exposed to severe soil erosion.
\end{abstract}

"Sorumlu yazar (Corresponding author): Ahmet ÇíLEK, acilek@cu.edu.tr 
This study aims to determine the annual soil loss for Göksu Basin by using the RUSLE erosion modelling method to map erosion regulation as an ecosystem service and its integration into sustainable management/planning studies. In the RUSLE method, a calculation is made using the precipitation factor (R), soil erosion susceptibility factor (K), slope length factor (L), slope steepness factor (S), Land Cover and Area Use Factors $(\mathrm{C})$ and erosion control factor $(\mathrm{P})$. The results obtained reveal the potential of factors to provide ecosystem services and provide critical information for landscape management.

Keywords: Regulatory ecosystem services, Soil erosion, Eastern Mediterranean basin, RUSLE

\section{GÍRISŞ}

Uzun bir oluşum sürecine sahip olan topraklar üzerinde yaşayan insan ve diğer bütün canlılar için yaşam ve besin kaynağının temelini oluşturduğu için en önemli doğal kaynaklardandır. Aynı zamanda yaşamlarını sürdürebilmeleri için gerekli olan hava ve su ile yiyecek ve yakıt gibi temel ihtiyaçların sağlanmasında ve bütün canlı yaşamının devamlılığında en önemli unsur olarak kabul edilmektedir [1]. Topraklar, hidrolojik döngünün sağlanması, bitkiler için fiziksel ortam, besin maddelerinin tutulması ve paylaşılması, atıkların ve organik atıkların dönüşümü, toprak verimliliğinin yenilenmesi ve başlica element döngülerinin düzenlenmesi olmak üzere temelde altı ana ekosistem hizmeti sunmaktadır [2].

Ancak son yıllarda toprakların yanlış kullanımı ve yanlış toprak işleme çalışmaları sonucunda çok kısa sürede ve büyük miktarlarda erozyonun meydana gelmesine ve bu kaynakların sürdürülebilir kullanımlarının azalmasına neden olmaktadır. Toprak erozyonu, tarımı, doğal kaynakları ve çevreyi ciddi şekilde tehdit ettiği için bugün dünyadaki en ciddi çevre sorunlarından biridir. Toprak erozyonu, zaman içinde meydana gelen doğal bir süreçtir ve erozyonla ilgili endişelerin çoğu, doğal oranın insan faaliyetleriyle önemli ölçüde arttığı hızlandırılmış erozyonla ilgilidir. Hızlandırılmış toprak erozyonu dünya çapında ciddi bir sorundur ve kapsamı, büyüklüğü, hızı ve bununla ilişkili karmaşık süreçler nedeniyle ekonomik ve çevresel etkisini doğru bir şekilde değerlendirmek zordur [3]. Bu yüzden erozyon çölleşme ve arazi bozulumunu etkileyen en önemi faktörlerden birisi hale gelmektedir. Dünyada yılda yaklaşık 24 milyar ton toprak erozyonu ile üst toprak kaybolurken [4], ülkemizde 285,5 milyon ton toprak her yıl aşınarak taşınmaktadır [5].

Toprağın kaybolması ile birlikte üzerinde yaşayan bitki ve hayvan varlığındaki çeşitlilik azalmakta, su kaynakları kirlenmekte ve hem karasal hem de sucul ekosistemler zarar görmektedir. Böylece taşınan topraklar ile akarsu, göl, baraj gibi su yapıları ekosistem işlevlerini sağlıklı bir şekilde yerine getirilemeyecektir. Ayrica erozyon sonucunda baraj rezervuarları çok kısa bir sürede taşınan materyaller ile dolacağı için barajların ekonomik ömürleri de kısalacaktır. Arazi örtüsünün değişmesiyle toprak erozyonunun değişiminin değerlendirilmesi, restorasyonun verimliliğini ve toprak erozyon kontrolünde ekosistem işlevlerinin eğilimini ve ekosistem hizmet değerlendirmesini anlamak için önemlidir. Ekosistemler, hizmetlerin sağlanması, düzenlenmesi, kültürel ve desteklenmesi dahil olmak üzere insanlara çeşitli faydalar sağlar. Tedarik hizmetleri, insanların ekosistemlerden elde ettikleri gida, yakıt, lif, tatlı su ve genetik kaynaklar gibi ürünlerdir. Düzenleme hizmetleri, insanların hava kalitesi bakımı, iklim düzenlemesi, erozyon kontrolü, insan hastalıklarının düzenlenmesi ve su arıtma dahil olmak üzere ekosistem süreçlerinin düzenlenmesinden elde ettiği faydalardır. Kültürel hizmetler, insanların ekosistemlerden ruhsal zenginleşme, bilişsel gelişim, yansitma, rekreasyon ve estetik deneyimler yoluyla elde ettiği maddi olmayan faydalardır. Destek hizmetleri, birincil üretim, oksijen üretimi ve toprak oluşumu gibi diğer tüm ekosistem hizmetlerinin üretimi için gerekli olan hizmetlerdir [6]. Peyzajın izlenmesi küçük ölçeklerde çok fazla bilgi sağlasa da, şiddetli toprak erozyonuna maruz kalan alanlarda toprak 
erozyon kontrolünü değerlendirmek için modellere dayalı değerlendirmelere ihtiyaç vardır.

Doğal kaynakların sürdürülebilir kullanımı için toprak erozyon miktarının mekânsal olarak belirlenmesi, sebep olduğu çevre ve ekonomi sorunlarını azaltılması amacıyla farklı erozyon modelleri geliştirilmiştir. Deneysel, kavramsal ve fiziksel temelli modeller olmak üzere üç tip erozyon modeli bulunmaktadır [7]. Erozyon modelleri genellikle mekânsal değişimi tanımlayarak iklim özellikleri, topografya, arazi örtüsü ve toprak özellikleri olmak üzere dört temel faktör üzerinden basit diferansiyel denklem kullanırlar. Ancak toprak kayıplarının doğruya en yakın tahminlerinde iki kısıtlayıcı faktör bulunmaktadır. Bunlardan birincisi modellerin yüksek belirsizlikleri ikincisi ise mekan ve zaman değişimleridir.

Deneysel modellerde en çok Universal Soil Loss Equation (USLE) modeli ve bu yöntemin geliştirilerek üretilen Revised Universal Soil Loss Equation (RUSLE) modeli kullanılmaktadır. Bu modeller mevcut veri sağlandığı durumda, değişkenler arasındaki istatistiksel anlamsal ilişkiyi tanımlarlar [8]. Deneysel modellerde yer gözlemi, yersel ölçüm, deney ve istatistiksel teknikler ile toprak kaybını ortaya çıkaran baskın değişkenlerin tanımlanması temel alınır [9-11]. Deneysel modeller karışı doğal süreçleri kullanamaz ve yalnız tasarlandığı ölçütle kullanılabilir. $\mathrm{Bu}$ yüzden deneysel modellerle erozyon tahminini oluşturmak hızlı olmaktadır ancak bu alanlar için uzun dönemlik veri setinin elde edilmesi gerekmektedir [12].

Bu çalışmada ülkemizdeki erozyon riskinin yüksek olduğu Akdeniz Bölgesi'nde bulunan Göksu Nehri Havzasi'nda Uzaktan Algılama (UA) ve Coğrafi Bilgi Sistemleri (CBS) teknolojisi kullanılarak RUSLE yöntemi ile toprak erozyon miktarı mekansal olarak tespit edilmesi amaçlanmıştır. Böylece RUSLE yönteminde UA ve CBS'nin uzaktan algılama ve CBS teknolojilerinin entegrasyonu ile elde edilen sonuçların ekosistem hizmetleri açısından mekânsal planlama çalışmalarına altlık veriler sağlaması hedeflenmektir.

\section{MATERYAL VE YÖNTEM}

\section{1. Çalışma Alanı}

Göksu Nehri Havzası, Doğu Akdeniz Bölgesinde ve Konya, Karaman ve Mersin illeri sınırları içerisinde yer almaktadır. Havza, Göksu Nehrinin oluşturduğu derin vadileri ve değişken topografyaya sahip bölgeyi temsil etmektedir. Havzanın yukarı kesimi Orta Toros Dağlarının zirvelerine kadar uzanır ve Göksu Nehri kuzeybatıdan güneydoğuya doğru ilerleyerek Akdeniz'e ulaşır. Havzada nehirden gelen alüvyallerin birikmesiyle oluşan Silifke ovası oluşmuştur ve denize döküldüğü yerde de Göksu Deltası oluşmuştur.

Göksu nehri karstlaşma ve karstik yapılara sahip Sertavul ve Taşeli Platolarını yararak denize dökülür. Nehir ağı ile oluşan vadi, Torosları Orta ve Batı olmak üzere ikiye ayırmaktadır. Yaklaşık 11000 km²'lik alana sahip olan Göksu Havzası'nda birçok yüksek alanlar bulunmaktadır. Bunlar, kuzeyde 1760 m yüksekliğe sahip Çoka Dağı ve $2480 \mathrm{~m}$ yüksekliğe sahip Özyurt Dağı yer almaktadır. Alanın doğusunda Midilli ve Kavaklı Dağı, güneyinde Alamusa Dağı ve batısında Akçalı Dağları, Akdağ, Kuşak Dağı, Çekiç Dağı, Karadağ ve Haydar Dağı bulunmaktadır. Havzanın deniz seviyesinden en yüksek yeri $2510 \mathrm{~m}$ ile Karadağ'dır.

Göksu Havzası, iklimsel yönden Akdeniz iklimi, iç bölümlerde karasal iklim yer almaktadır. İklimsel bu farklılıktan dolayı bitki örtüsü yönünden de Akdeniz ve İran-Turan bitki coğrafyası arasında geçiş bölgesinde bulunmaktadır. Bölge yazın az miktarda yağış alırken, kışın yoğun yağış almaktadır. Akdeniz iklimine sahip bölge bitki örtüsü bakımından makilikler, 700-900 m yüksekliklere kadar uzanan kızılçam ormanları, 800-1400 yüksekliklerde meşe ormanlar1, 1200-2100 m yüksekliklerde ise göknar, ardıç ve sedir ormanları bulunmaktadır [13]. Orman üst sınırı olan 2100 metreden yüksekte yer yer subalpinik bitki örtüsü yayılışı görülmektedir. 
Alan dâhilinde ortalama eğim 6,11 derece olurken en düşük eğim 0 , en yüksek eğim ise 89 dereceyi bulmaktadır. Yükseklik 0 ile $2509 \mathrm{~m}$ arasında yer almakta ve topoğrafya, arazi örtüsü, toprak, yaban hayatı, hidrolojik yapı, jeoloji ve iklim bakımından önemli bir karakteristik yapıya sahiptir.

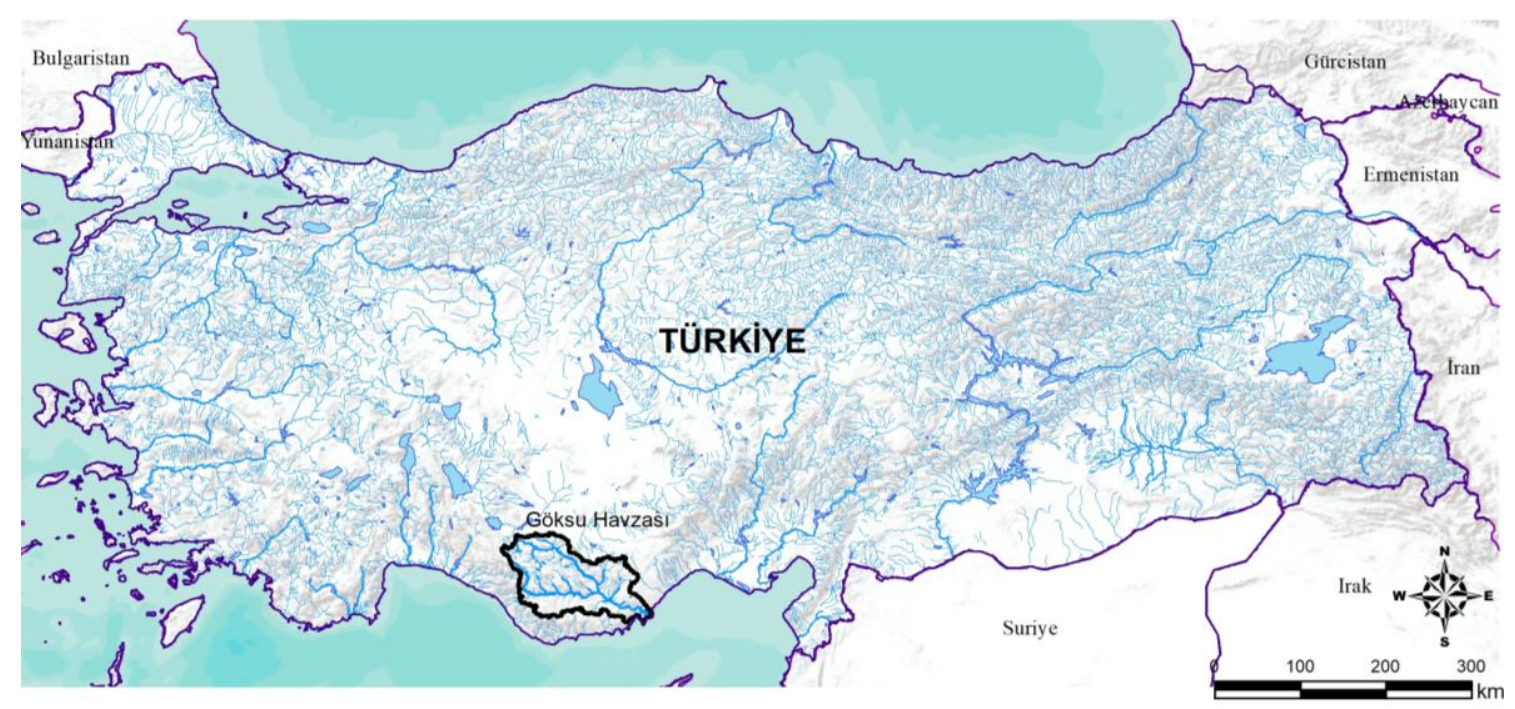

Şekil 1. Çalışma alanının konumu

\subsection{Veriler}

Göksu havzasında toprak kaybını modellemek için RUSLE modelinde kullanılan temel veriler farklı kurumlardan ve kuruluşlardan temin edilmiştir. Modelde, iklim, topografya, toprak, arazi örtüsü/ arazi kullanımı ve doğal bitki örtüsüne ait veriler kullanılmıştır. Çalışma alanı içinde ve çevresinde yer alan büyük klima, 180 adet küçük klima istasyonu verileri temin edilmiştir. RUSLE-K faktörü, Köy Hizmetleri Genel Müdürlüğü'nün yayınladığı Türkiye Büyük Toprak Grupları "K" Faktörleri raporundan [14] faydalanılarak elde edilmiştir. Topografik verileri $30 \mathrm{~m}$ yersel çözünürlüğünde ASTER ve SRTM (Shuttle Radar Topography Mission) uydu verilerinden temin edilmiştir. Arazi örtüsüne ait bilgiler ise Landsat 8 uydu görüntülerinden üretilen Normalize edilmiş Bitki Örtüsü İndeksi (NDVI) verileridir.

\subsection{Yöntem}

1985 yılında ABD Tarım Bakanlığı ve araştırmacılar USLE modeli üzerinde çalışmış ve 1987'de revize edilerek RUSLE modeli geliştirilmiştir [7]. RUSLE modeli için, USLE modeline yeni eklemeler getirilerek yenilenmiştir. Sadece tarımsal araziler için değil, aynı zamanda kentsel kullanımlara, orman kullanımına, otlak ve mera alanlarına ve karayollarındaki eğimli alanlara kadar geniş kullanım alanı ortaya konulmuştur. RUSLE yönteminde uzun dönemde yağmur damlası etkisi ve yüzey akışının oluşturduğu toprak kaybı yıllık hektar başına ton olarak altı farklı değişkenden oluşan Eşitlik 1 yardımıyla tahmin etmektedir [15].

$A=R * K * L * S * C * P$

Burada; A: ortalama toprak kaybını (ton/ha/yıl), R: Yağış aşındırma faktörünü, K: Toprak erozyon duyarlılığ faktörünü, L: Eğim uzunluğu faktörünü, S: Eğim dikliği faktörünü, C: arazi örtüsü ve kullanım faktörünü, $P$ ise erozyon kontrol faktörünü temsil etmektedir. 


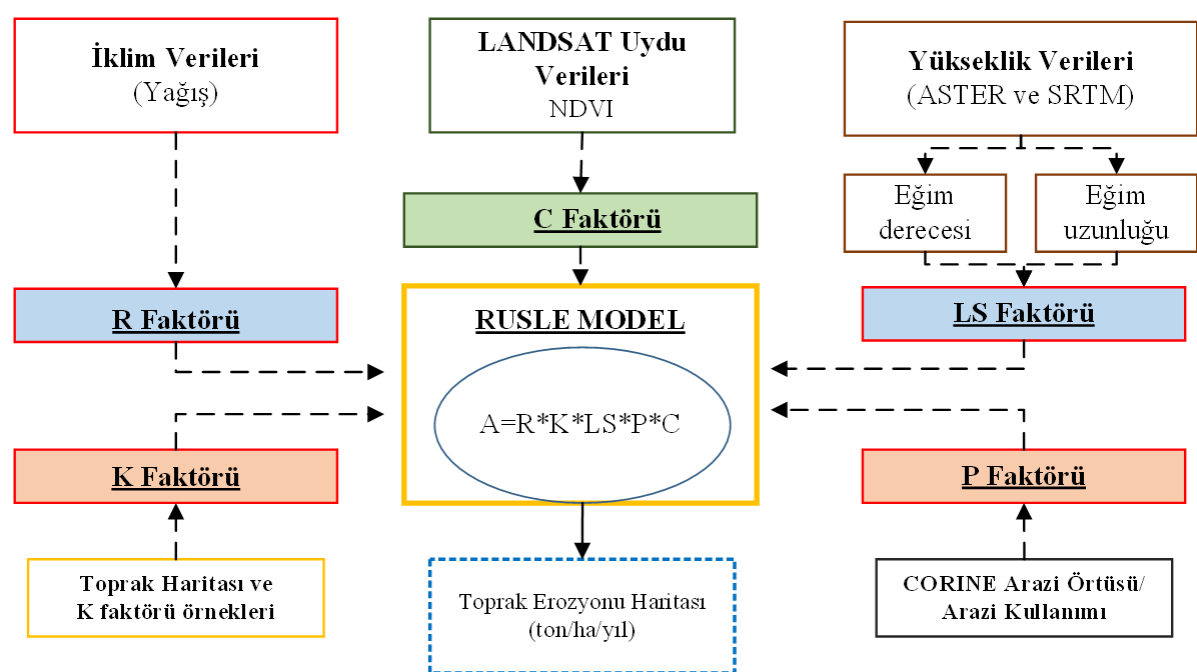

Şekil 2. RUSLE yöntemi akış şeması

\section{BULGULAR}

RUSLE yöntemi ile model için gerekli değişkenlerin üretilmesi ve eşitlikte belirtildiği gibi çarpılarak hektar başına düşen yıllık erozyon miktarı hesaplanmıştır.

\subsection{Yağış Aşındırma Faktörü (R)}

Yağış Aşındırma faktörü (R), RUSLE eşitliğinde yağışların toplam kinetik enerjileri ile 30 dakikalık maksimum yoğunluklarının çarpımı ile elde edilir. $\mathrm{Bu}$ faktör, toprak kaybı oranını etkileyen önemli faktörlerden birisidir ve yağışın miktarı ile yoğunluğuna bağlıdır [16]. Yüzey akışı ve yağışlar tarafından oluşan yüzey ve oluk erozyonunu temsil eder. Yağışın 30 dakikadaki maksimum yoğunluğunda olan yağışların toplamının yıllık yağış miktarının toplamına oranı olarak kullanılmaktadır. $\mathrm{Bu}$ değerler meteoroloji istasyonlarında yaygın bir şekilde ölçülmediğinden birçok hesaplama yöntemi geliştirilmiştir. $\mathrm{Bu}$ kapsamda yağışın yıllık ve aylık ortalamalarının hesaba katıldığı Wischmeier ve Smith [17] tarafından geliştirilen eşitlik kullanılmıştır (Eşitlik 2).

$$
R=\sum_{i=1}^{12} 1,735 \times 10^{1,5 \operatorname{Logpi}^{2} / P-0,8188}
$$

Burada: R: Yağış aşındırma faktörü pi: Aylık ortalama yağış $(\mathrm{mm}) \mathrm{P}$ : Yıllık ortalama yağışı ( $\mathrm{mm})$ ifade eder.

Meteoroloji Genel Müdürlüğü'nden 1975-2020 tarihleri arasında Büyük Klima ve Küçük Klima istasyonlarına ait yağış verileri temin edilmiştir. İstasyon bazlı elde edilen veriler enlem, boylam ve yükseklik değerleri ile eşleştirilerek ANUSPLIN yazılımı aracılığıyla ince-plaka yumuşatma eğrileri fonksiyonu (thin-plate smoothing spline functions) uygulanmıştır. ANUSPLIN paketi, kapsamlı istatistiksel analizler, veri tanılama ve mekansal olarak dağıtılmış standart hatalar aracılığıyla ince plaka yumuşatma eğrilerini kullanılarak gürültülü çok değişkenli verilerin şeffaf analizi ve interpolasyonuna olanak sağlar. Ayrıca esnek veri girişi ve yüzey sorgulama prosedürlerini de destekler. $\mathrm{Bu}$ yöntemle bağımlı ve bağımsız değişkenler ilişkili olduğunda birçok yüzey yüksek doğrulukla hesaplanabilmektedir. Ayrıca az sayıda veriler ile değişkenler arasında dönüşümlere izin vererek standart hataları hesaplar ve küçük sapmaları düzeltir. Bu düzeltmenin özellikle yağış verileri veya doğal olarak pozitif veya negatif olmayan diğer verilerde de uygun olduğu tespit edilmiştir [18]. 17 adet meteoroloji istasyonundan alınan verilerden 12 aylık ortalama yağış haritası üretilmiş ve yukarıda belirtilen eşitlik ile RUSLER Faktörü elde edilmiştir (Şekil 3) 


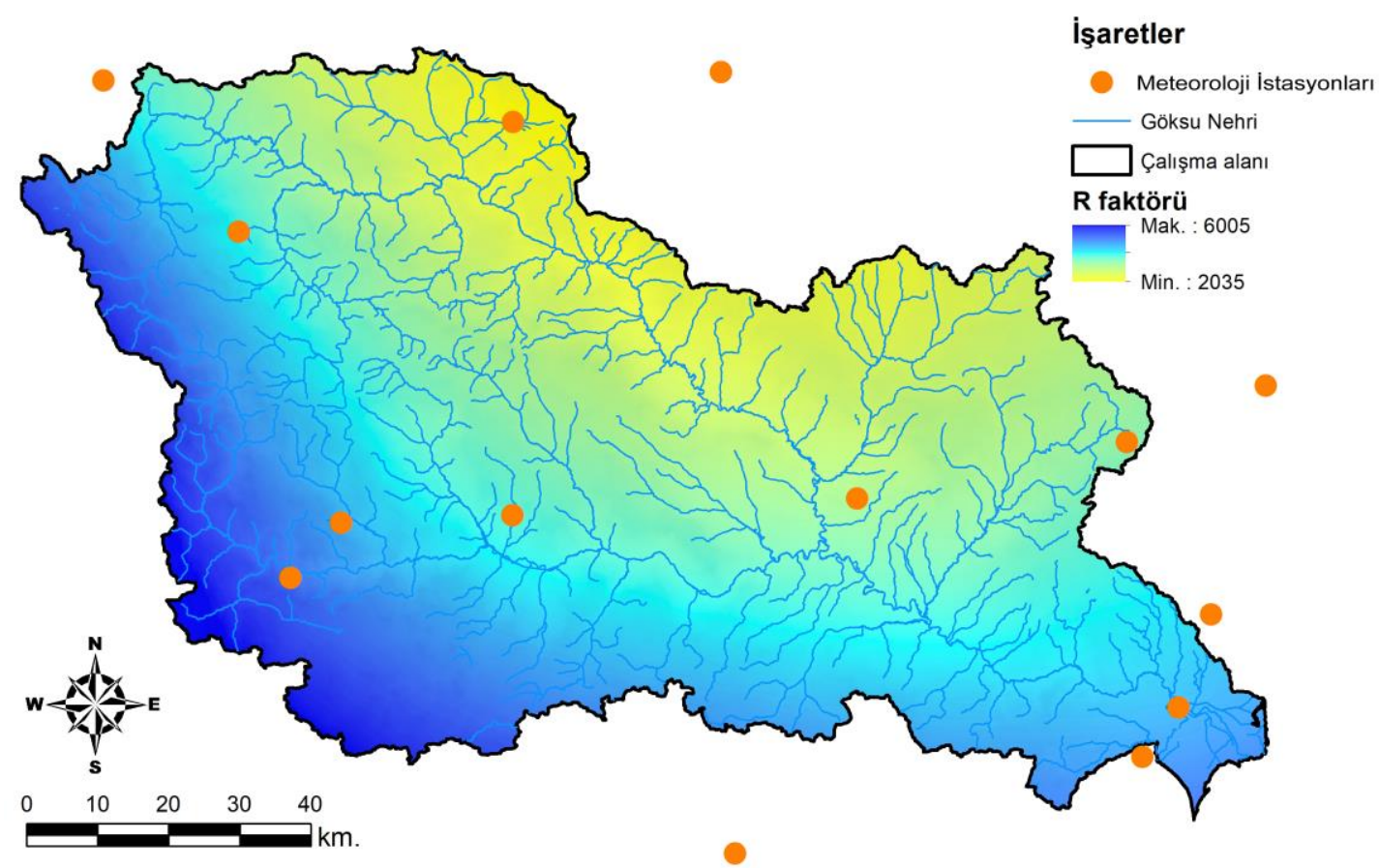

Şekil 3. Göksu havzası RUSLE yağış aşındırma (R) faktörü

\subsection{Toprak Aşınabilirlik Faktörü (K)}

Toprak aşınabilirlik (K) faktörü Universal Soil Loss Equation (USLE) içerisinde \%9 eğim ve 22,1 metre eğim uzunluğundaki bir arazi ünitesinde birim erozyon indisi ile hektardan kaybolan toprağın ton olarak ifadesidir. Fiziksel ve kimyasal olarak farklı özelliklere sahip olan topraklar farklı derecelerde aşınırlar. Toprakların fiziksel özellikleri, aşınabilirlik derecelerine etkili en önemli hususlardır [14].

K faktör değerleri, Türkiye'de 10 adet Köy Hizmetleri Araştırma Enstitüsü tarafından Büyük Toprak Gruplarına göre 0-15 ve $15-30 \mathrm{~cm}$ derinliklerde örnekler alınarak oluşturulmuştur. Oluşturulan noktasal $\mathrm{K}$ faktörleri değerleri, her büyük toprak grubu için çoklu regresyon yöntemi uygulanarak $\mathrm{K}$ faktörü haritası oluşturulmuştur (Şekil 4). Oluşturulan modellerde K faktörü hedef veri olurken, her bir toprak grubuna ait ortalama kil, silt, kum değerleri, $30 \mathrm{~m}$ çözünürlükte yükseklik verisi, eğim verisi, enlem ve boylam değerleri tahmin edici değişkenler olarak kullanılmıştır. Tahmin edilen $\mathrm{K}$ faktörü değerleri en düşük 0,001 en yüksek 0,080 olmak üzere ortalama 0,021 değerini almaktadır. Nokta değerlerinin \%20'si model geçerliliği için sınanmış ve (RMSE) ortalama toplam hata 0,010 olarak belirlenmiştir ( $\mathrm{p}=0,05$ alınmıştır).

\subsection{Topografik Faktörler (LS)}

RUSLE modeli eğim faktörünü eğimin derecesi ve eğimin uzunluğunun etkisi olarak kullanmaktadır. Eğimin uzunluğu (L), yüzey akışının oluşacağı noktadan eğimin azalarak toprağın veya yüzey akışının birikmeye başlayacağı yere kadar olan yatay mesafedir [17]. LS faktörü, 22,13 m uzunluğundaki ve \%9 eğime sahip bir alandaki toprak kaybını temsil eder. Bu faktör yamacın eğimini ve yamacin uzunluğunu dahil ederek Moore ve Burch [19-21] tarafindan önerilen Eşitlik 3'e göre belirlenmektedir (Şekil 5).

Pow ((flowacc)*resolution/22,1,0,6)

*Pow $(\operatorname{Sin}(($ slope $) * 0,01745) / 0,09,1,3))$ 


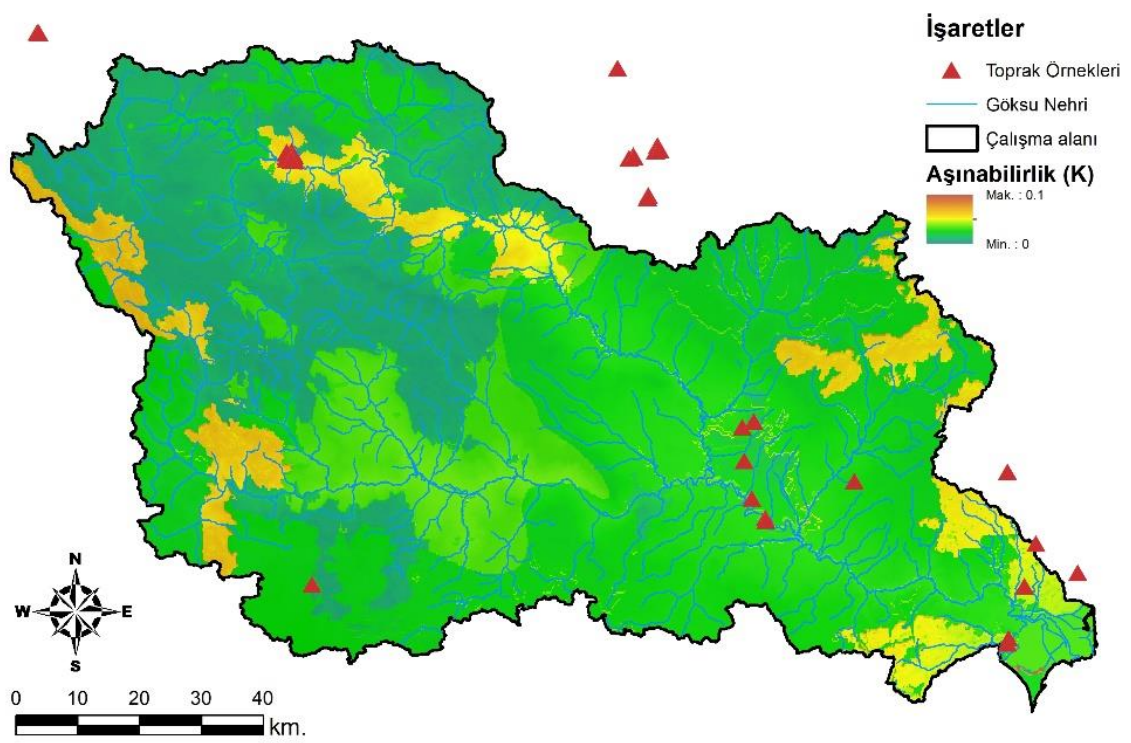

Şekil 4. Göksu Havzası RUSLE toprak aşınabilirlik (K) faktörü

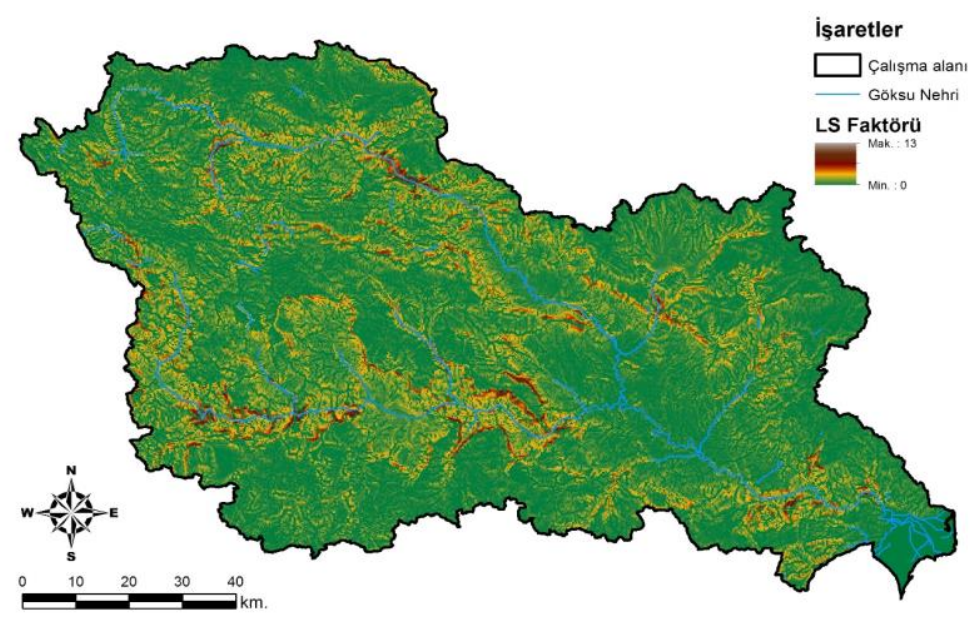

Şekil 5. Göksu Havzası RUSLE eğim uzunluğu ve engebelilik (LS) faktörü

\subsection{Arazi Örtüsü ve Alan Kullanım örtüsünden yoksun, düşük biokütleye sahip arazi Faktörleri (C) kullanımlarında ise C faktörü artmaktadır.}

Erozyonun oluşmasına neden olan yersel durumu ifade eden arazi örtüsü ve alan kullanım faktörü RUSLE modelinde en önemli faktörlerden birisidir [22]. Topraktaki biyokütle ve bitki örtüsü kapalılığının artması ile C faktörü azalırken, bitki
Çalışmada C faktörünün hesaplanmasında 2018 y1lına ait Landsat 8 görüntülerinden elden edilen Normalize Edilmiş Vejetasyon İndeksi (NDVI) verileri kullanılmıştır. RUSLE modeli C faktöründe bitki örtüsünün kapalılığını niceliksel 
olarak Eşitlik 4'teki gibi NDVI verileri kullanılarak tahmin edilmektedir (Şekil 6) [23,24].

$$
C=e^{(-\alpha(N D V / / \beta-N D V I)))}
$$

$\mathrm{Bu}$ eşitlikte $\alpha$ ve $\beta$ : NDVI ve $\mathrm{C}$ faktörüne ait istatistiksel ilişkiyi belirleyen parametreler Van der Knijff ve arkadaşları [23] tarafından yapılan çalışmalar sonucunda $\alpha$ ve $\beta$ için en uygun değerler sırasıyla 2 ve 1 olarak belirlenmiştir.

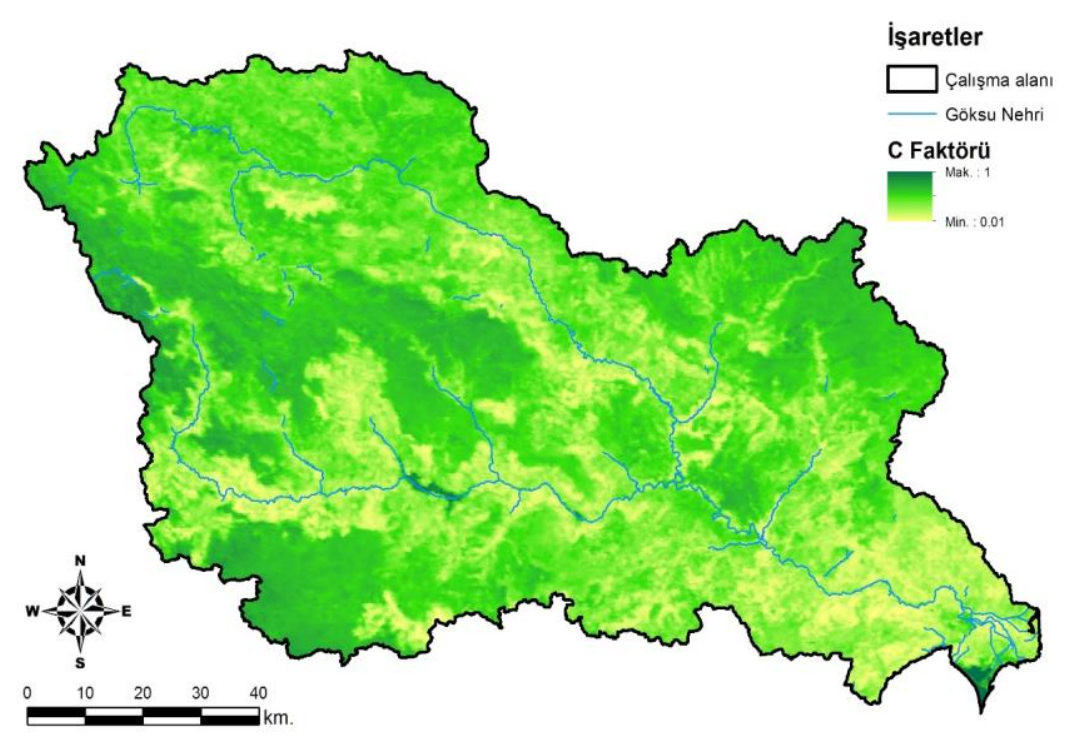

Şekil 6. Göksu havzası RUSLE C faktörü

\subsection{Erozyon Kontrol Faktörü}

Erozyon kontrol faktörü (P) arazide erozyon kontrolü veya önlemine yönelik herhangi bir koruma uygulamasının olup olmadığıyla ilgilenir. Küçük ölçekli çalışmalarda bu bilgiler kolaylıkla temin edilebilmektedir. Ancak havza ölçeğinde verilerin temin edilmesi güç olduğundan arazi örtüsü bazında erozyon kontrol faktörü değerleri sınıflandırılmış ve P faktörü olarak kullanılmıştır (Çizelge 1). Birçok çalışmada ise verilerin temin edilememesinde dolayı bu faktör değeri tüm alanlar için 1 olarak alınmaktadır [25-28]. Bu çalışmalar erozyon kontrolü uygulamadan önceki durumun belirlenmesi aşamalarında kullanılması uygun olabilmektedir.

\subsection{RUSLE Modeli Sonuçları}

RUSLE toprak erozyon yönteminde tüm faktörlere bağlı olarak A faktörü (ton/ha/yıl) CBS ortamında tahmin edilmiştir (Şekil 7). Model sonuçlarına göre çalışma alanında erozyon 0 ile 2297 ton/ha/yıl arasında hesaplanmıştır. Ortalama erozyon 46,2 ton/ha/y1l, standart sapma ile 98,1 , toplam erozyon miktarı ise 9.985 .626 ton/y1 olarak tahmin edilmiştir.

Çizelge 1. RUSLE P faktörü değerleri [29]
\begin{tabular}{|c|l|c|}
\hline $\begin{array}{c}\text { Sıra } \\
\text { no }\end{array}$ & Arazi örtüsü/Arazi kullanımı & $\begin{array}{c}\text { P } \\
\text { değeri }\end{array}$ \\
\hline 1 & Yoğun bitki örtüsü & 1 \\
\hline 2 & Seyrek bitki örtüsü & 0,8 \\
\hline 3 & Yerleşim alanı & 1 \\
\hline 4 & Su yüzeyleri & 1 \\
\hline 5 & Çalılıklar & 1 \\
\hline 6 & Tarımsal alanlar & 0,5 \\
\hline 7 & Nadasa bırakılmış alanlar & 0,9 \\
\hline 8 & Çıplak alanlar/kayalıklar & 1 \\
\hline
\end{tabular}




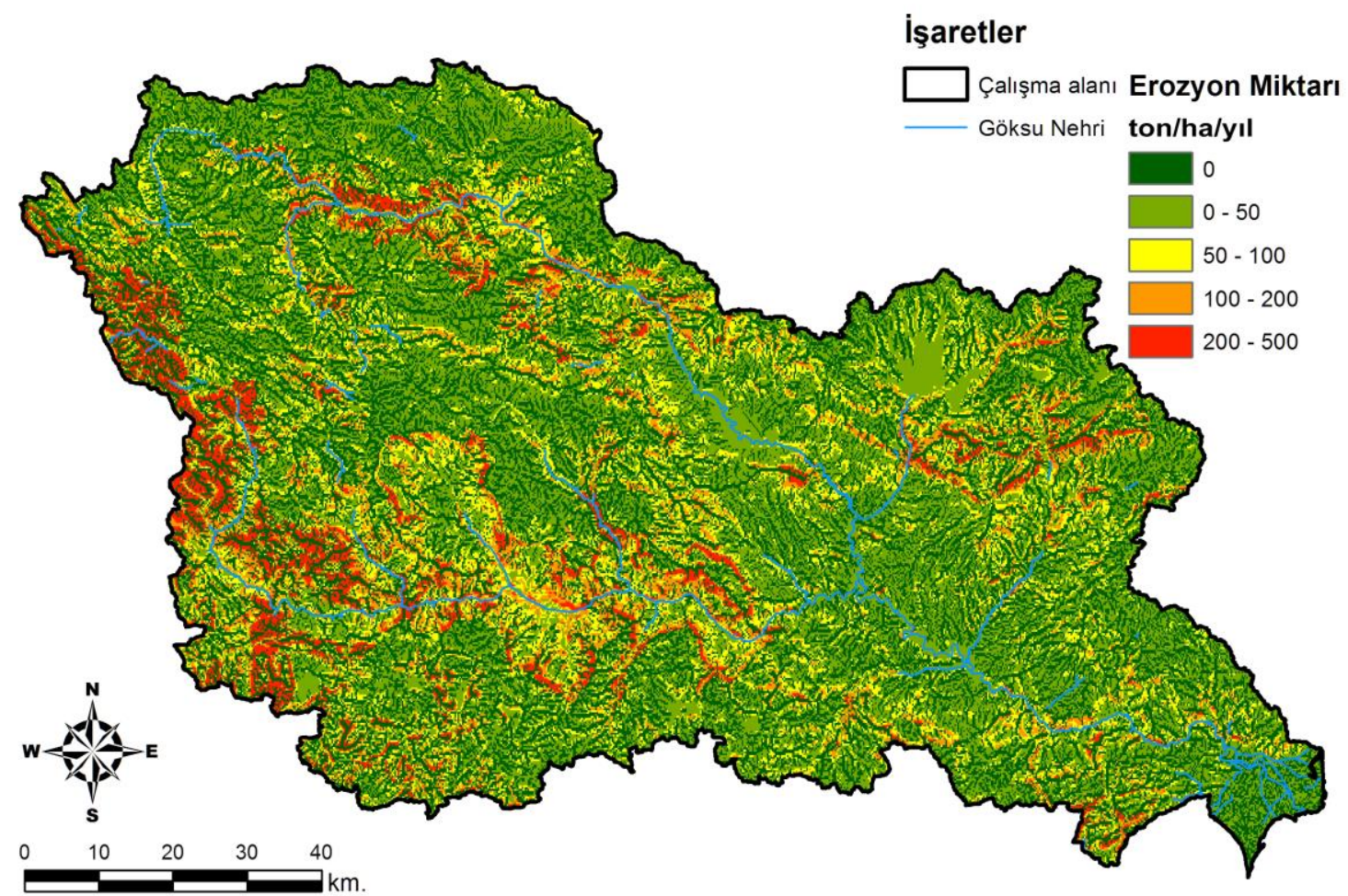

Şekil 8. Göksu havzası RUSLE tahmini erozyon haritası

Erozyon riski açısından RUSLE yöntemi sonucunda oluşturulan erozyon risk analizi haritasına göre; erozyon riskinin olmadığı alanlar $\% 42$ oranında olduğu görülmektedir. Çalışma alanının \%31'lik kısmı 0-50 ton/ha/yıl arasında, \%14'lük kısmın 50-100 ton/ha/y1l aralığında olduğu, geriye kalan \%28'lik kısmın ise 100 ton/ha/yıl'dan büyük olduğu hesaplanmıştır. En yüksek riskin, havzanın batısında bulunan ve dağlık ve engebeli alanlarda olduğu görülmektedir. Ekosistem servislerinde toprak koruma planlamasinda ortaya konulacak durum gruplamalardaki değerler ile toprak kaybı toleransı arasındaki ilişkinin belirlenmesidir. Mevcut toprak kaybı miktarını toprak koruma planlarında kabul edilebilir düzeye indirgeyebilmek için alanda hangi faktörlerin erozyon üzerinde olumsuz etkilediği matematiksel denklemlerle ortaya konulmaktadır. Böylece alanlar için elde edilen sonuçların yanı sıra arazi kullanma ve koruma önlemleri planlamasının da uygulanmasında önemli bir veri olarak kullanılacaktır.

\section{SONUÇLAR}

Dünyada olduğu gibi Türkiye'de de toprak kaybının neden olduğu en önemli etkenlerden birisi erozyonudur. Arazi morfolojisindeki değişkenlikler, iklimsel etkiler, arazi örtüsü/arazi kullanımı ve toprak özelliklerinin etkileşimleri sonucu doğal erozyon meydana gelirken, insanların doğaya kontrolsüz bir şekilde müdahalesi sonucunda erozyon bir afete dönüşmektedir. İnsan etkisinin en önemli göstergesi olan Arazi örtüsü/Arazi kullanımı üzerinde meydana gelen değișimler ekosistemler üzerinden büyük etkiler meydana getirmektedir. Havzalarda gerçekleşebilecek bozulma diğer sistemlerin de etkin bir şekilde çalışmasını engelleyecektir. Ekosistem hizmetleri açısından havzalarda sürdürülebilir planlama ve yönetim çalışmalarının gerçekleştirilebilmesi için potansiyel toprak kaybı miktarının ve mekânsal dağılımının belirlenmesi önemlidir. Bu bağlamda 
çalışma, dağlık havza ölçeğinde potansiyel toprak erozyonu alanlarının mekansal dağılımını ölçmek ve haritalamak için jeo-uzamsal analiz araçlarının potansiyelini göstermektedir.

Sonuç olarak yoğun toprak kaybı olan bölgelerde bitki örtüsünün restorasyonunu geliştirmek için büyük çalışmalar gereklidir. Ayrıca oyuk alanlarında uygun biyolojik bariyerlerin ve jeoteknik tesislerin inşa edilmesi gerekmektedir. Yoğun ve yanlış tarım uygulamaları erozyonu ve erozyondan kaynaklı bozulmaları hızlandırmaktadır. Hızlandırılmış toprak erozyonu, küresel sorunlar su kalitesi ve yenilenebilirlik, insan kaynaklı karbon emisyonlarının dengelenmesi, küresel ısınmanın azaltılması, gıda ve çevre güvenliğii, biyoçeşitlilik gibi birçok konu ile bağlantılıdır. $\mathrm{Bu}$ nedenle, toprak koruma, erozyon kontrolü ve erozyona uğramış toprakların restorasyonu önemli politika zorunluluklarına sahiptir. Bu bağlamda erozyonun yüksek olduğu tarım sektörü için temel amaç, çiftçileri ve arazi yöneticilerini, toprağı ve çevreyi iyileştirmek için onarıcı arazi kullanımı ve uygun toprak/mahsul/ hayvan yönetimi uygulamalarını benimsemeye teşvik etmek olmalıdır. Ayrıca, tarım için elverişsiz yüksek erozyon riski bulunan alanlar için çiftçilere alternatif geçim kaynakları sağlayacak endüstriyel transfer ve kırsal kalkınma gibi programlar geliştirilmelidir. Böylesi alanlar için büyük ölçekli bir koruma ve izleme programı kurulmalıdır. $\mathrm{Bu}$ açıdan çalışma alanında toprağı koruyacak önlemler alınarak etkili bir şekilde işletilmesi kaçınılmaz olmaktadır.

\section{KAYNAKLAR}

1. Blanco-Canqui, H., Lal, R., 2008. Principles of Soil Conservation and Management. Springer, Dordrecht, The Ohio State University, Columbus, OH, USA, ISBN: 978-1-40208708-0, 129.

2. Daily, G.C., Matson, P.A., Vitousek, P.M., 1997. Ecosystem Services Supplied By Soil. In G.C. Daily, ed. Nature Services: Societal Dependence on Natural Ecosystems, Island Press, Washington, DC, 113-132.
3. Erkal, T., Y1ldırım, Ü., 2012. Soil Erosion Risk Assessment in the Sincanlı Sub-watershed of the Akarçay Basin (Afyonkarahisar, Turkey) Using the Universal Soil Loss Equation (USLE). Ekoloji, 21(84), 18-29.

4. ÇMTUEP, 2005. Çölleşme ile Mücadele Türkiye Ulusal Eylem Planı, Çölleşme ile Mücadele Ulusal Koordinasyon Birimi, Çevre ve Orman Bakanlığı Yayınları No: 250, Ankara, 124.

5. Berberoglu, S., Cilek, A., Kirkby, M., Irvine, B., Donmez, C., 2020. Spatial and Temporal Evaluation of Soil Erosion in Turkey Under Climate Change Scenarios Using the Paneuropean Soil Erosion Risk Assessment (PESERA) Model. Environmental Monitoring and Assessment, 192(8), 491.

6. Millenium Ecosystem Assessment, 2005. Ecosystems and Human Well-being: Biodiversity Synthesis, Millennium Ecosystem Assessment, Island Press, Washington, DC.

7. Lal, R., 1994. Soil Erosion Research Methods. St. Lucie Press. Soil and Water Conservation Society, Delray Beach, Ankeny, 340.

8. Kadupitiya, H.K., 2002. Empirical Evaluation and Comparative Study of Use of Erosion Modelling in Small Catchments in Naivasha, Kenya, Master Tezi, ITC, Enschede.

9. Petter, P., 1992. GIS and Remote Sensing for Soil Erosion Studies in Semi-arid Environments, Doktora Tezi, University of Lund, Lund, 250.

10. Güney, Y., 2018. Frekans Oranı Yönteminin Erozyon Duyarlılık Analizinde Kullanımı: Selendi Çayı Havzası (Manisa) Örneği, Toprak Bilimi ve Bitki Besleme Dergisi, 6(2), 73-85.

11. Cilek, A., Berberoglu, S., Donmez, C., Unal Cilek, M., 2020. Generation of HighResolution 3-D Maps for Landscape Planning and Design Using UAV Technologies. Journal of Digital Landscape Architecture, 5, 275-284.

12. Elirehema, Y.S., 2001. Soil Water Erosion Modeling in Selected Watersheds in Southern Spain, IFA, ITC, Enschede, 42.

13. Ünal, A., 1989. Karaman-Mut Karayolu Doğusunda Kalan Bölgenin Fitososyolojik ve Fitoekolojik Yönden Araştırılması, Selçuk Üniversitesi Fen Bilimleri Enstitüsü Doktora Tezi, Konya, 150. 
14. Doğan, O., Cebel, H., Küçükçakar, N., Akgül, S., 2000. Türkiye Büyük Toprak Grupları "K" Faktörleri, Ankara Araştırma Enstitüsü Müdürlüğü Yayınları, Ankara.

15. Renard, K.G., Foster, G.R., Weesies, G.A., McCool, D.K., Yoder, D.C., 1997. Predicting Soil Erosion by Water: A Guide to Conservation Planning with the Revised Universal Soil Loss Equation (RUSLE), Agriculture Handbook 703 USDA, Washington.

16. Naqvi, H.R., Devi, L.M., Siddiqui, M.A., 2012. Soil Lossprediction and Prioritization Based on Revised Universal Soil Lossestimation (RUSLE) Model Using Geospatial Technique. International Journal of Environmental Protection, 2(3), 39-43.

17. Wishmeier, W.H., Smith, D.D., 1978. Predicting Rainfall Erosion Losses: a Guide to Conservation Planning USDA Agricultural Handbook, ABD Tarım Bakanlığı, Washington, DC, ABD.

18. Hutchinson, M., 2007. ANUSPLIN Version 4.3 .

19. Moore, I.D., Burch, G.J. 1986a. Modeling Erosion and Deposition, Topographic Effects Trans. Am. Soc. Agric. Eng. 29, 1624-1630.

20. Moore, I.D, Burch, G.J., 1986b. Physical Basis of the Length-Slope Factor in the Universal Soil Loss Equation, Soil Sci. Soc. Am. J., 50, 1294-1298.

21. Mitasova, H., Hofierka, J., Zlocha, M., Iverson, L.R., 1996. Modelling Topographic Potential for Erosion and Deposition Using GIS, Int. I. Geographical Information Systems, 10(5), 629-641.

22. Toy, T.J., Foster, G.R., Renard, K.G., 1999. RUSLE for Mining, Construction and Reclamation Lands, Journal of Soil and Water Conservation, 54(2), 462-467.

23. Van der Knijff, J.M., Jones, R.J.A., Montanarella, L., 2000. Soil Erosion Risk Assessment in Europe, EUR 19044 EN, Office for Official Publications of the European Communities, Luxembourg.

24. Van Leeuwen, W.J.D., Sammons, G., 2004. Vegetation Dynamics and Soil Erosion Modeling Using Remotely Sensed Data (MODIS) and GIS, Tenth Biennial USDA
Forest Service Remote Sensing Applications Conference, 5-9 Nisan 2004, UT. US Department of Agriculture Forest Service Remote Sensing Applications Center, Salt Lake City.

25. Wachal, D.J., Banks, K.E., 2007. Integration GIS and Erosion Modeling: A Tool for Watershed Management, ESRI 2007 International User Conference, No: UC1038.

26. Tağıl, Ş., 2007. Tuzla Çayı Havzasında (Biga Yarımadası) CBS-Tabanlı RUSLE Modeli kullanarak Arazi Degradasyonu Risk Değerlendirmesi, Ekoloji, 60, 11-20.

27. Erdoğan, M.A., Esbah, H., Berberoglu, S., 2016. Erosion Risk Mapping Using RUSLE with GIS: Case Study of Büyük Menderes River Basin of Turkey, Int. J. of Safety and Security Eng., 6(2), 132-140.

28. Çilek, A., Berberoğlu, S., Dönmez, C., 2014. PESERA ve RUSLE Erozyon Modellerinin Akdeniz ve Ege Havzaları Örneğinde Karşılaştırılması. V. Uzaktan Algılama ve CBS Sempozyumu, İstanbul, Türkiye.

29. United States Department of Agriculture, USDA, 1981. Handbook no. 282. 
